\title{
Supply Chain Quality Management
}

\author{
Lynn A. Fish \\ Canisius College \\ United States of America
}

\section{Introduction}

In today's economy, it is no longer business versus business, but rather supply chain versus supply chain. To compete, supply chain members must learn to seamlessly integrate, grow, and develop business functions. Traditional quality management practices have been and will continue to be used to address many of these supply chain integration issues. With this in mind, current managerial thinking is advancing the notion of supply chain quality management. Supply chain quality management is a systems-based approach to performance improvement that integrates supply chain partners and leverages opportunities created by upstream and downstream linkages with a focus on creating value and achieving satisfaction of intermediate and final customers (Foster, 2008; Robinson \& Malhotra, 2005). The intent of the chapter is to (1) review the positive impact of quality management on supply chain management, (2) present cases of supply chain improvements through quality management with a focus on the processes of design, production, delivery, support, and supplier-customer relationships, and (3) discuss the best practice recommendations, relationship between total quality management factors and transition to supply chain quality management that follow from these results.

\section{Positive relationship between quality management and supply chain management}

Although there are several definitions of quality, simply put, quality can be defined as meeting or exceeding customer expectations (Evans \& Lindsay, 2002). According to the American Society for Quality, the definition of quality is "A subjective term for which each person or sector has its own definition. In technical usage, quality can have two meanings: 1 . the characteristics of a product or service that bear on its ability to satisfy stated or implied needs; 2 . a product or service free of deficiencies. According to Joseph Juran, quality means "fitness for use;" according to Philip Crosby, it means "conformance to requirements." (American Society for Quality Online Glossary, 2011) Quality tools exist and include, but are not limited to: cause analysis (cause-and-effect diagrams, pareto charts, and scatter diagram), evaluation and decision-making tools (decision matrix and multi-voting), process analysis (flowchart, failure modes and effects analysis, mistake-proofing, and spaghetti diagrams), data collection and analysis (box and whisker plot, check sheet, control chart, design of experiments, histogram, scatter diagram, stratification, and surveys), idea creation (affinity diagram, benchmarking, brainstorming, and nominal group technique), an improvement project (Gantt chart and Plan-Do-Study-Act continuous improvement model), 
and management tools (relations diagram, tree diagram, matrix diagram, L-shaped matrix, arrow diagram, and process decision program chart) (Tague, 2004).

Total quality management is a set of quality practices that seek to continuously improve quality in processes. The eight key principles of total quality include (Monczka et al., 2009):

1. Define quality in terms of customers and their requirements.

2. Pursue quality at the source.

3. Stress objective rather than subjective analysis.

4. Emphasize prevention rather than detection of defects.

5. Focus on process rather than output.

6. Strive for zero defects.

7. Establish continuous improvement as a way of life.

8. Make quality everyone's responsibility.

Supply chain management is an approach to integrating suppliers, manufacturers, distributors and retailers, such that products are produced and distributed at the right quantities, to the right location, at the right time, with the mutual goals of minimizing system wide costs and satisfying customer service requirements (Simchi-Levi et al., 2008). In other words, supply chain management synchronizes a firm's processes with its suppliers and customers with the goal of matching the materials, services and information with customer demand (Krajewski et al., 2010). Critical supply chain processes include product design, production, delivery, support, and supplier-customer relationships. To succeed in today's environment, managers need to integrate their goals effectively to compete in the dynamic, global economy and focus on the final customer as the driver for improvements. Supply chains compete based upon cost, quality, time and responsiveness. Supply chain improvement tools include, but are not limited to process improvement tools of flow charting, flow diagrams, service blueprints, process analysis, process re-engineering, link charts, multi-activity analysis, backward chaining, and Gantt charts.

Quality is one of the most important factors for companies in their relationship between suppliers and customers. In fact, quality is so critical that today's executives question whether their companies should be participating in global sourcing as many global suppliers are not able to meet quality requirements (Brockwell, 2011). Positive relationships between quality management and supply chain management exist. To begin, quality management improvements in reducing process variation directly impact on several supply chain performance measures. With continuous quality management improvement, defects and therefore, process and production variation, are reduced. In turn, as consistency in the supply chain improves due to the variation reduction, cycle times are reduced (the time between two successive replenishments) and on-time delivery improves (Flynn \& Flynn, 2005).

Quality management practices, such as design for manufacturability, whereby product and process decisions are developing in new products simultaneously, and effective product designs geared toward the final customer requirements result in less product and process variation. While variance reduction in the processes obviously leads to quality improvements, consideration to the processes used during design enables management to switch from one product to another quicker. Therefore, design for manufacturability leads to quicker setup times between products (Flynn \& Flynn, 2005). Quicker setup times allows companies to reduce lot sizes as less cycle (inventory needed between two successive replenishments) and safety stock (the amount of inventory required to protect against deviations from average demand during lead time) is required (Simchi-Levi et al, 2008). 
As fewer defects are created, the amount of inventory in the supply chain is reduced. Supply chain members move only 'good' units, and not 'defective' units through the supply chain. Quality management practices reduce process variance, which has a direct impact on supply chain performance measures, such as inventory and time measures (Flynn \& Flynn, 2005). As process variation is reduced, leading to more quality units and fewer defective unit moving through the supply chain, the cycle time will also improve. With fewer defective units moving through the supply chain, delivery dependability improves. Similarly, cycle time improvements result in less inventory 'in the way' of supply chain movement as there is less need for safety and cycle stock inventory, and fewer defective units need to be scrapped or replaced (Simchi-Levi et al., 2008).

Quality efforts to reduce variation have many positive results, including pipeline inventory reduction (Flynn \& Flynn, 2005). Pipeline inventory (the amount of inventory between members of the supply channel including work in process inventories between manufacturing operations) is held as a function of manufacturing, supply and delivery cycle times. Through quality management, as the number of defects in the supply chain decreases and cycle times are shortened, simultaneously the total and pipeline inventory are reduced (Simchi-Levi et al, 2008). As already noted, pipeline inventory is also improved through variance reduction.

A quality improvement leading to a reduction in defective units, and therefore a reduction in rework, has a positive impact upon the supply chain as cycle times are reduced, schedules are met and customer response times improve (Flynn et al., 1995; Mefford, 1989). Fewer defective units in the system allow the remaining units to move through the supply chain faster, which is noted by improved cycle times. As companies are able to move product faster through the supply chain, schedules and the customers' demands can be met faster. This allows an improved synchronization and integration across the entire supply chain (Ferdows et al., 2004).

The adage 'garbage in, garbage out' advocates strong relationships between suppliers and buyers with respect to quality. Supplier certification programs and registration systems, such as ISO9000, assist companies to obtain quality items at the source. Prompt and reasonable supplier feedback also assists with providing quality inputs to the system. Utilizing statistical process controls throughout the supply chain aids in variation reduction, ensures quality inputs and reduces work-in-process in the supply chain system. Quality at the source, feedback and process controls ensure quality throughput in the system and therefore, reduces inspection time for raw materials, in-process inventory, and finished goods (Flynn \& Flynn, 2005). The end result of supplier certification programs is less time is needed to stop the product and inspect for 'quality', which in turn, reduces cycle and transportation times (Heiko, 1990).

Constantly changing suppliers merely due to price, increases the variation in the materials and time elements for the supply chain. Product variation and information accuracy is negatively impacted. Certified suppliers and long-term relationships can positively impact on both quality and supply chain initiatives (Heiko, 1990; Kaynak \& Hartley, 2008; Trent \& Monczka, 1999). In these relationships, suppliers and buyers reap joint improvement driven by mutual interdependence, open and complete exchange of information, and win-win shared rewards. In these relationships, due to improved and increased exchange of information, supplier's product design changes are minimized, visibility to future purchase volume requirements is increased, and access and visibility to new product requirements is improved. Suppliers gain from a reduction in new product development time, production lead time, ethical treatment, and accurate, timely payment of invoices. 
To summarize, quality management practices are associated with supply chain performance improvements. Therefore, quality management and supply chain management strategic goals and initiatives need to be pursued simultaneously as customers drive supply chain management and quality initiatives.

\section{Quality and supply chain improvement}

As discussed, there is a positive and direct relationship between quality and supply chain management. While the quality management movement started in the United States in the 1970's, the supply chain management movement is much 'younger', gaining momentum with the turn of the 21st century. Within a supply chain, important business processes affect customer satisfaction: design, production, delivery, support, and supplier-customer relationship processes. What quality techniques and tools are available to drive supply chain management improvements?

\subsection{Design}

We continue with a discussion of several cases whereby quality methods were instrumental in supply chain management improvements, starting with the design process. The design process, which is critical for company and supply chain survival, includes all activities that translate customer requirements, new technology and past learning into functional specifications for a product, process, or service. With supply chains growing to include global partners, time elements squeezing the quality attributes of items and development speed increasing, it is not surprising that the design process has received considerable attention in the past decade. It is imperative that the products and processes to deliver the item to the final customer are jointly designed. A wide variety of quality methods can be used to improve supply chains during the design phase including concurrent engineering, design for assembly, value engineering, and quality function deployment.

Simultaneous, or concurrent, design of products and processes within companies, under the umbrella of concurrent engineering has been successful in product design at Intel and Microsoft. Concurrent engineering, which brings together various functional specialists, is a process to bridge the gap between design and manufacturing with the goal of shortening time to market and improving quality. As supply chain management competition increases, a current design trend is to draw upstream suppliers into the new product development processes (which we will address in greater depth shortly). Due to technological and innovation demands, supply chain concurrent engineering, for products such as electric cars, required suppliers further up the supply chain (beyond Tier 1 suppliers) to participate in the design process to increase competitiveness, reduce time to market and increase quality (Pilkington \& Dyerson, 2002). As supply chains increase participation of all members in design efforts, it is imperative that hidden costs of new product development acceleration, such as the form of skipping steps - particularly information communication and allocation of resources toward non-profitable, trivial innovation that drives out more profitable ones, be carefully monitored. Also, it is imperative that during the design phase, splitting design and production of coupled processes should be avoided.

Design for manufacturability provides a method for designing parts that are easy to manufacture and assemble, with cost and cycle time reduction and quality improvements as a result. Continuing in this vein of simultaneous activity, an emphasis on synchronizing 
product design decisions with supply chain management decisions, extends the concept of design for assembly to 'design for supply chain' (Hulta \& Swan, 2003; Joglekar \& Rosenthal, 2003; Lee \& Sasser, 1995) and 'design for logistics' (Simchi-Levi et al., 2008). Design for supply chain addresses the simultaneous design for materials across the different supply chain levels, while design for logistics emphasizes consideration during design to the processes used to move the items through the supply chain, such as packaging, transportation, timing of value-added processes and standardization. Using design for manufacturability, the automotive industry analyzed the make/buy decision with a focus on supply chain processes which resulted in product and production capability optimization, concluded that simpler products should be outsourced while complex designs remain in-house, and supported the strategic importance of the product in the make/buy decision (Novak \& Eppinger, 2001).

Value engineering, a disciplined approach to eliminating waste from products and processes (APICS, 2002), can positively impact upon both supplier and buyer's bottom-line as demonstrated by the automotive industry where sharing information strengthened the relationship, reduced time to market, improved product quality and reduced costs (Blaney, 2005). Correspondingly, due to the lack of information sharing and value engineering practices, a 'cut-throat attitude' continues to penetrate the construction industry (Blaney, 2005). Extending value engineering to the supply chain should include evaluating all supply chain processes and not just a single process. As an example, Schneider Electric, a global electrical equipment manufacturer, jointly partners with their suppliers to achieve beneficial product results as well as significant supply chain cost, quality and time improvements (Avery, 2002). Joint value engineering efforts resulted in a material change for the component, resulting in cost savings for both members and a quality improvement.

Quality Function Deployment, a methodology to match the customer's needs with technological capabilities, has proven to be beneficial in designing products such as the 1992 Cadillac, and for companies such as Ford, General Motors, Motorola, and AT\&T (Evans \& Lindsay, 2002). Extension to the supply chain involves using Quality Function Deployment across supplier-customer boundaries to capture the final customer's voice and integrate it with supply chain processes. Japanese managers also indicate that the Quality Function Deployment process itself can be utilized to improve supply chain quality, technology management, and supply chain operating initiatives (Chu-Hua et al., 2002).

As previously noted, while supplier-customer integration across the supply chain for all processes is a major trend, integration in the design process can lead to cost reduction, supply chain competitiveness and improvements in quality, product safety, resource planning and materials management. John Deere and Motorola's highly successful new product development are well-known cases in this area. At John Deere, through the supplier development engineering program, a significant cost reduction resulted; however, suppliers and John Deere noted that all members must share technology, risk and accountability. Similarly at Motorola, the need for design resources and a focus on costs were emphasized. Integration typically involves organizational changes including cross-functional integration of multifunctional teams and supplier advisory councils. While a trend in supply chain management is toward strategic sourcing, the question of when to incorporate suppliers into new product development is still debatable. Early supplier design involvement is a concurrent engineering approach between suppliers and buyers that takes advantage of the supplier's design capabilities. Suncor Energy utilized internal personnel, contractors and suppliers to develop a unified strategy to address all phases of the product life cycle. Results 
indicate a cost reduction, planning and cycle time reduction, and a significant success rate in wells drilled (Monczka et al., 2009). The results highlight the need to develop a unified, joint strategy and importance of communication.

\subsection{Production/ delivery, and support processes}

We continue our discussion by highlighting the integration of quality and supply chain management improvements during the production, delivery and support processes. The production process is responsible for manufacturing the product from inputs through processes to outputs, while delivery processes are responsible for delivery of the product to the customer. Support process, although they do not add direct value to the product, provide an infrastructure for the core processes. Useful quality management tools in production, delivery and support processes include (but are not limited to) process improvement techniques, Six Sigma quality, performance measurement, Kaizen, benchmarking, value stream mapping, value analysis, and re-engineering.

A quality management survey used in northern Italian businesses uncovered several problems including information communication issues, excessive repetition of technical activities and production configuration errors, that negatively impacted upon the company and the supply chain members (Salvador \& Forza, 2004). As a results, the order acquisition and fulfillment processes were changed. Recently, Target Corporation used supply management teams to develop a world-class supply base, reduce costs, improve cycle times and accelerate time to market (Murphy, 2010). The team utilized various quality tools to evaluate value creation in the supply chain activities.

A Six Sigma Quality Program, credited to Motorola, indicates that a process is in control to within tolerance limits of +/- 6 standard deviations from the centerline in control charting, which given natural process variation relates to 3.4 defects per million opportunities. Six Sigma programs have been effectively utilized in services, manufacturing, education and government. For example, Starwood Hotels utilized a Guest Satisfaction Index survey under its Six Sigma program to improve quality, reduce costs, increase speed and customer responsiveness, and efficiency (Monczka et al., 2009). Similarly a printed circuit board company's six sigma project to identify the root causes, key points and critical outputs resulted in changes to the production processes (Lee et al., 2009).

Value analysis and value engineering are useful methods to improve the product, processes or both during new product development to ensure that the product or service fulfills its intended function at the lowest total cost. Value analysis and value engineering was successfully used in several industries, including the U.S. Department of Defense. At the U.S. Department of Defense, life cycle costs are reduced through value engineering processes focused on low-cost systems for equipment, procedures, and supplies that are safe, reliable, and maintainable (Benstin et al., 2011). Value analysis and value engineering were successful used in the chemical, plastic, electronic, transportation and packaging industries to improve production performance, product quality, safety, and customer service while reducing transaction costs and inventory costs.

Benchmarking, whether informal or formal, is an effective method to improve quality, decrease costs, decrease lead time, improve dependability, and reduce shortages. Benchmarked firms improved their supply chains significantly on various measures over firms that chose not to benchmark (Heizer \& Render, 2006). Twenty-five years after the growth of benchmarking, a recent multinational survey of benchmarking practices indicates 
that benchmarking is still an effective improvement tool (Adebanjo et al., 2010). A benchmarking study of supply chain processes from different industries that used dependency analysis and data envelopment analysis favored efficient supply chains as higher financial performers (Reiner \& Hofmann, 2006).

\subsection{Supplier-customer relationship management}

Since purchased components account for over $55 \%$ of the cost of goods and suppliers are responsible for over $50 \%$ of a firm's product quality problems, the relationship between the supplier and buyer is critical. Quality is the most important factor for companies in their relationship between suppliers and customers (Sila et al., 2006). Therefore, supplier and customer relationship management processes can enhance or inhibit competition. Critical processes to this relationship include communication, mutual assistance on new product development, and training. Strong relationships develop win-win relationships, trust, openness and honesty. However, this is easier said than done. As recently as the turn of the century at Whirlpool, little integration between supply chain members existed as different levels of the supply chain had different quality standards and goals (Roethlein et al., 2000). In fact, raw material providers did not understand where their products would finally end up, let alone the quality goals of members further down the chain.

Supplier certification programs incorporate quality and delivery factors into the vendor selection process, which improves quality and delivery while reducing costs. Similarly, when applied to supply chain processes, a certification process assists with supplier selection and supply base optimization, a process to find the optimal number and mix of suppliers. At Alcoa, a world leader in aluminum and related products production, a comprehensive supplier certification program jointly improves quality and reduces costs for Alcoa and their suppliers (Monczka et al., 2009). As a follow-up to supplier selection, supplier performance rating systems assist with developing a stronger linkage between supplier and buyer through developing a win-win relationship for both partners, and assist with standardizing and homogenizing quality goals throughout the supply chain. Process improvements also assist with communication improvements to communicate quality requirements with suppliers, and using performance measurement systems, supplier improvement programs can be developed.

Improvements to the supplier-customer relationship management exist in the eight key principles of Total Quality Management. To begin, communication of quality requirements from the buyer in term of final customers is critical. Supplier certification processes assist with pursuing quality at the source, while statistical quality controls can monitor and control product and process issues. Objective (measured) instead of subjective (opinionbased) facts should be shared between supply chain members. A system to monitor and correct defects throughout the supply chain, without pointing blame is imperative. Performance data should guide quality and supply chain improvements. With respect to sourcing, supply managers can use data to develop preferred supplier lists, provide feedback to current suppliers, and monitor and improve relationships, products and processes. Total Quality Management programs between suppliers and buyers should focus on prevention of defects, and product and process variance reduction through programs such as supplier certification programs. Monitoring should shift from product monitoring to process monitoring for consistency and reducing variation. A working supplier evaluation and selection system, benchmarking, reduction of duplicated processes, and knowledge 
transfer between functional units and across member boundaries can assist with the shift to process evaluation. ISO9000, the Malcolm Baldrige National Quality Award, and similar awards are critical factors to consider in the selection system. Another critical aspect in this relationship is developing a viable measure and understanding by supply chain members for process capability. Supplier evaluation and supply base rationalization processes can assist with improving supply chain quality throughout the system as variation between suppliers is reduced and product quality can be improved. As previously discussed, value analysis and value engineering can assist in developing a culture of continuous improvement throughout the supply chain. Similarly including - and rewarding, suppliers for participation in improvement programs can enhance the relationship and reap benefits for both members. The supplier-buyer relationship between supply chain members requires that quality start at the top. That is, it is imperative that company visions, goals and strategies be aligned for the betterment of both companies. Joint projects, shared technology, buyer-supplier councils, and collaborative relationships can enhance the relationship. The end result is a culture of continuous improvement throughout the supply chain, and as a result, a highly effective, competitive one.

In recent years, supplier-buyer linkages, whose main purpose was to procure materials, have been extended into design, information exchange, special services, distribution and marketing. Co-makership is a process whereby suppliers and buyers work to establish a strong partnership with a few suppliers based upon information sharing and trust (Flynn \& Flynn, 2005). Co-makership efforts can reduce cycle time, increase inventory turnover and a higher on-time delivery rate. Co-makership encourages quality management practice utilization and supply chain improvements through supplier evaluation, supply base reduction to facilitate long-term relationships, collaboration on product design activities, and proactively managing quality and delivery of parts (Flynn \& Flynn, 2005).

\subsection{Summary of quality and supply chain management}

A recent study highlighted the similarities and differences between supply chain and operations managers as to quality integration (Foster \& Ogden, 2008). Supply chain managers emphasized using benchmarking, complaint resolution, design for the environment, Enterprise Resource Planning, supplier development, change management, focus groups and supply chain process improvement more than operations managers. While both supply chain and operations managers realize the value of ISO9000, operations managers emphasize this system slightly more than supply chain managers. Supply chain management is focused on improving future performance, while operations managers are process-oriented. Supply chain management must move beyond its transactions cost-based perspective focused on the buyer-supplier relationship. Since customers drive supply chain management and quality management, integration of quality and supply chain goals will develop a more competitive organization. Integration difficulties arise due to a lack of structure, organizational culture, reward system, and amount or lack of communication across functions (Pagell, 2004).

Our review highlights the various tools used in the key supply chain processes of design, production, delivery, support and supplier-customer relationship management, and reveals that traditional quality management practices applied to process management hold the key to addressing supply chain management issues. While in the past supply chain managers and operations managers approached quality differently, in order to be competitive, today's 
practices must be inter-organizational, quality and supply chain oriented. There is a need to advance current thinking from traditional firm-centric and a product-based mindset to an inter-organizational supply chain involving customers, suppliers, and partners. Therefore, quality and supply chain management need to be integrated and incorporated into managers decision-making as Supply Chain Quality Management. Supply Chain Quality Management is a systems-based approach to performance improvement that integrates supply chain partners and leverages opportunities created by upstream and downstream linkages with a focus on creating value and achieving satisfaction of intermediate and final customers (Foster, 2008; Robinson \& Malhotra, 2005). We continue with a discussion of supply chain quality management.

\section{Supply chain quality management}

\subsection{Total quality management factors \& supply chain quality management}

In Supply Chain Quality Management, the six Total Quality Management factors that are related to supply chain performance are leadership, strategic planning, human resources management, supplier quality management, customer focus, and process management (Azar et al., 2010).

With respect to leadership and in keeping with W. Edwards Deming, it is top management's responsibility to provide support, commitment and accept responsibility for quality. Similarly, Juran noted that top management is responsible for quality delivery, but he related its impact to the financial impact. As companies move toward supply chain quality management, leadership is essential in order to direct processes, overcome cultural issues, and manage human resources that differ between companies along the supply chain. Leadership has a critical role in Supply Chain Quality Management to guide and direct individual planning and supplier management, build supply chain linkages toward improving quality and performance, and encourage and promote supply chain quality management through collaboration, communication and integration.

Strategic planning involves developing a clear mission, long-term strategy, and long and short-term goals. With respect to supply chain quality management, top management is responsible for developing the supply chain linkages that will positively impact upon quality, and for bridging the gap between the various organizational levels with respect to their quality expectations. To improve quality and supply chain performance, strategic plans are currently focused on supplier evaluation and supply base rationalization. Supply chain partners need to jointly create missions, strategies and goals as well as share values. Perceptual differences need to be resolved to encourage a reliable, trusting supply chain network.

Organizational and cultural differences between supply chain members creates a significant challenge for achieving supply chain and quality goals. Communication, collaboration and integration must be effectively addressed through human resource management. Within supply chain quality management, human resource management focuses on using quality tools and techniques by cross-functional teams, such as quality and sourcing teams. Best supply chain quality management practices indicate a cooperative culture between buyers and suppliers, close internal communication, and teamwork are essential. Training and empowerment programs are likely to increase in importance in the future. Employee training programs focused on customers, while not directly improving customer service measures, will have a positive impact through the indirect relationship with employee 
relations. Effective people skills are a necessity to manage relationships and partnerships in supply chain quality management.

The current trend with respect to supplier quality management is a supplier selection and evaluation process that encourages long-term relations with a few qualified suppliers capable of achieving necessary quality requirements (Monczka et al., 2009). Through performance reviews which include relevant quality measures, buyers should provide suppliers any necessary education and technical assistance. Best practices in supply chain quality management includes Strategic Supply Management which entails quality management, encourages continuous improvement throughout the supply chain, and includes suppliers in new product development and process development (Azar et al, 2010). Through Strategic Supply Management, suppliers assist in providing low defect levels in incoming materials, and as we noted earlier, this improves downstream quality and positively affects inventory management as safety and pipeline inventories are reduced, and in turn, positively impacts upon supply chain costs and cycle times. Strategic Supply Management can be seen as a simultaneous, bilateral effort between buyer and supplier firms to improve procurement, supply, and distribution processes. Strategic Supply Management initiatives that positively impact upon quality and performance include:

- Reducing supply bases and establishing closer relationships with their suppliers,

- Buyers working closely with suppliers and potentially launching joint strategic projects,

- Earlier supplier involvement and joint problem-solving efforts, leading to the early discovery of quality problems,

- Inter-firm production scheduling breaks down barriers between organizations, resulting in shorter production runs, and

- Developing a favorable quality culture based upon top-management commitment to improving beyond organizational boundaries.

Customer focus represents a commitment to customers through performance evaluation that includes customer satisfaction and customer involvement in design and feedback processes. Product design quality is significantly impacted upon by the positive or negative relationship between buyers and suppliers. Companies that focus on ensuring quality and building close supplier relationships while integrating key suppliers into product and service design will be extremely competitive in the marketplace (Azar et al., 2010).

Process management can be enhanced through incorporating sound quality management practices, such as statistical process control, fool-proofing process design, empowering employees with quality and process training, and sound product designs focused on the customer, and a collaborative design process. Best supply chain quality management practices encourage establishing an effective data collection system for customer feedback and requirements in order to improve product and service design, process management, and performance. Suppliers with effective, operating quality control systems will be positive partners in collaborative new product development efforts.

Best practices in product and process design in supply chain quality management can be found through incorporating Design for Manufacturing, concurrent engineering, Quality Function Deployment, and value engineering, and include:

- Translating customer requirements into product and service design requirements early, linking design and production, and taking supplier capabilities into account.

- $\quad$ Building quality into products and services through using appropriate engineering and quantitative tools during new product development across company boundaries. 
- Cross-functional communication across company boundaries, reducing new product development time and using practices to "design it right the first time".

- Building trust between supply chain members so that customer requirements can be designed into the product and associated service.

- $\quad$ Linking design and production across company boundaries by incorporating supplier capabilities into design parameters.

Several issues during design for companies to address include how to build trust, how to improve communication, how to share hidden costs associated with concurrent engineering, how to share new technologies that are mutually developed, material and component issues, whether to utilize suppliers further up the supply chain in new product development, and product complexity issues. Quality tools and techniques can assist managers in answering these questions.

To improve production, delivery and support processes, a supply chain should build upon the basic business best practices by:

- Documenting, managing and controlling value-added production, delivery and support processes within and across the supply chain.

- Using systematic methods to identify significant variations in process performance and output quality, determining root causes, taking corrective actions and verifying results with a focus on the final customer.

- Continuously improving processes to achieve improved cycle times, better quality, and overall operational performance for all supply chain members.

- Innovating to achieve breakthrough performance for the entire supply chain system.

Quality management practices, such as Six Sigma, performance measurement, Kaizen, benchmarking, value stream mapping, value analysis, and re-engineering have proven and will continue to prove to be beneficial to achieving these best practices during production, delivery and support. Specific supply chain management issues with extending the basic best practices include developing a joint total costing approach, sharing data - specifically costs and potentially proprietary information, developing mutually beneficial methods, and developing logistics and inventory management systems beneficial to all members. Again, traditional quality tools can assist managers with these issues.

Issues surrounding building trust, defining performance measures, and developing a system that is mutually beneficial, highlight the difficulties faced in supplier-customer relationship management. Quality techniques such as supplier certification systems, training, and communication top the list on ways to improve this process. These systems take advantage of traditional quality management techniques to manage and lead teams and people. The best practice for a supply chain merely involves extending a company's best practice to include all upstream and downstream partners, as in:

- Defining, monitoring and controlling supplier performance requirements while developing partnering relationships within the entire supply chain from raw materials through the final customer.

Perhaps, this is the most difficult best practice to achieve as people relationships, particularly across company and cultural boundaries, are the most difficult to manage. Various issues on how to develop mutually beneficial work practices, quality practices, and performance across different global supply chain cultures and technology levels, and what organizational structures should be used, exist. Again, quality management practices offer methods to develop solutions. 


\subsection{Relationships between total quality management factors in supply chain management}

Since Supply Chain Quality Management requires the six Total Quality Management factors (leadership, strategic planning, human resource management, supplier quality management, customer focus, and process management). We continue with a discussion of the relationships between each of these factors (Foster, Walin \& Ogden, 2011; Kaynak \& Hartley, 2008; Kuei et al., 2008; Yeung, 2008). Leadership has a direct impact upon Supply Chain Quality Management through human resource management, strategic planning, customer focus, and supplier quality management, which in turn each impact upon process management, and ultimately, supply chain performance. Additionally, strategic planning has a direct impact upon human resource and customer focus.

Leadership is a critical component of Supply Chain Quality Management as top management directs and manages the resources of a supply chain. With this in mind, leadership directly impacts upon the cultural, process management, supply management, and human resources management issues within the supply chain. In developing competitive supply chains, it is imperative that management integrate quality processes with suppliers and customers to enhance the product's quality performance. Top management support of quality improvements in the organization extend to strategic integration with suppliers as over $50 \%$ of a company's quality problems can be attributed to suppliers. Therefore, top management strongly supports quality initiatives with suppliers through teamwork, close internal communication, and developing a cooperative culture that fosters trust and collaboration. Interestingly, these same strategic views are not always shared by middle managers, and many companies fail to address the gap that exists between top and middle management with regard to supplier-buyer integration. Interestingly, supply chain and operations managers approach quality from different perspectives as supply chain managers approach it from a supplier-buyer perspective, which promotes collaboration, supplier development and complaint resolution, while operations managers focus on processes and procedures. With respect to quality initiatives, both types of managers use data analysis, job training, project management, surveys and customer relationship management to foster continuous improvement.

Continuing our discussion of the relationships between the six Total Quality Management factors within Supply Chain Management, human resource management requires a different skill set to manage the supplier-buyer relationship than in the past. Today's strategic sourcing managers need relevant training and empowerment to develop strategic relationships with key supply chain partners. However, top management needs to realize that while training does not directly impact upon a company's customer focus, there is an indirect and valuable experience between training and customer focus through improved employee relations. Clearly, effective people management practices and skills are a critical supply chain management practices as relationships and partnerships must be effectively managed. Quality intensive firms assist in supplier-buyer relationships as teamwork, communication and a cooperative culture is advocated, which also supports trust and collaboration between two companies. A quality focus by both buyers and suppliers also demonstrates a common shared value system that resonates throughout the supply chain and enables value-added products and services to be distributed to the final customer.

With the average manufacturing firm spending more than half of its sales dollars on purchased components and services, it is easy to see why supplier management is critical to developing competitive supply chains. Top and middle managers consider supplier-buyer 
quality as the number one issue to focus on in improving quality. Supplier quality management has a direct and positive relationship with product and service design, inventory management, process management and performance throughout the supply chain. These relationships support the concept that quality management practices are interdependent in the supply chain and the need to analyze quality improvements through a systems approach. Strategic supply management efforts, such as creating long-term buyersupplier relationships, reduction of the supply base, formal supplier measurement systems, and strategic supply management integration, have a direct, significant impact upon timebased and cost-related operational efficiency of a supply chain. Time-based improvements in delivery speed, reliability and inventory turnover, and reduction of production cycle time, and cost-related improvement through total and unit cost reduction, and ease of modification to engineering changes, can be attributed to strategic supply management. In turn, time-based and cost-related improvements impact upon on-time shipments and cost of quality, which then leads to improvement in customer satisfaction as customer complaints are reduced, product reliability and customer relations improve. Ultimately, these efforts result in superior supply chain performance as market share, sales volume and profitability increase. Strategic supply management efforts are not constrained by the industry, type of processes, firms size, or markets, and should be pursued through each linkage in a supply chain.

Through involvement in product and service design, suppliers can more effectively meet the buyer's requirements, and therefore, positively impact upon quality. The supplier-buyer relationship impacts upon product design quality as the buyer must balance supplier development to ensure quality with building closer relationships and integration efforts. Failure to balance these efforts may lead to poor quality components or future quality issues between the members. There is a positive relationship between a supplier's quality system and the level of supplier involvement in product design as suppliers with effective quality control systems are more likely to be constructive partners in new product development efforts and less likely to be a hindrance. Positive supplier involvement in new product development is also related to project team effectiveness, and therefore, human resource issues between members.

Firms with comprehensive and operating quality management system have a culture of continuous improvement engrained in them. Therefore, supply chain members will find that companies with operating quality management systems more readily adapt to supply chain integration. Therefore, to create competitive supply chains, it is in the purchasing functions best interests to seek relationships with companies that have operating, quality management systems - even if slightly different approaches to quality management exist. In general, quality management systems represent a comprehensive effort to continuously improve - and adapt to changing conditions.

In competitive supply chains, inventory is exchanged for information as the ease of information exchange facilitates flexibility and responsiveness, reduces costs and improves quality throughout the supply chain. Therefore, an effective information system and associated processes to gather and distribute information forward - and backward, in a supply chain is a requirement. Information accuracy is critical to improving product and service design, processes and supply chain performance. Due to different cultures, organizational structures, information systems, and personnel, a 'one-size' fits all strategic approach will not be appropriate to manage the relationships, transition and information requirements with all suppliers and buyers in a supply chain. 


\subsection{Transition to supply chain quality management}

Today, organizations need to transition from the traditional supply chain model where quality is built through quality in purchasing and processes through a paradigm shift to an integrative, competent supply chain quality management model that leads through design and management of an innovative, quality supply chain. This process requires managers to navigate four distinctive stages to eliminate gaps: 1) emphasis on supply chain strengths by all members; 2) critical success factors need to be identified to develop competencies; 3 ) emphasis by members on infrastructure and supply chain climate; and 4) continuous improvement through supply chain quality practices (Kuei et al., 2008). To bridge these gaps, four drivers of supply chain quality are identified: supply chain competence, critical success factors, strategic components, and supply chain quality practices (Kuei et al., 2008). Supply chain competence, which is the collective learning of all supply chain members, is represented by organizational, managerial, technical and strategic capabilities and skills within or across the supply chain over time. Supply chain competence is the knowledge that allows the supply chain to compete and competitors have difficulty emulating. Dimensions to competence include product quality, delivery reliability, supplier/buyer trust, operational efficiency, and delivering value/innovation to the customer. Critical success factors include the ability of a supply chain to respond to different customer requirements through a customer focus, supplier relationships, quality of information technology systems, externally focused process integration, and supply chain quality leadership. Supply chain quality management should focus on the elements of quality management, culture, technology management, supplier participation, supply chain configuration design and strategic planning, into the core strategic processes of manufacturing, product development, technology management, international sourcing and customer engagement. Supply chain quality practices, such as supplier-buyer quality meetings, quality data and reporting, supply chain quality office, and supply chain optimization and policy deployment, promote a customer-focused supply chain that achieves supply chain deliverables.

Best practice recommendations to assist with the transition include the following (Kuei et al., 2008):

- Identifying areas of potential joint cooperation between supply chain members with a focus on delivering value and innovation to the end customer.

- Training for all supply chain members in supply chain quality management.

- Developing an ongoing, learning culture.

- Developing a collaborative information system to manage and monitor supply chain processes.

- Utilizing innovative technologies.

- Developing supply chain relationship characterized by trust, flexibility, communication and cooperation through quality management, cultural management, technology management, supplier participation, supply chain design and strategic planning.

- Regular, planned supplier-buyer meetings to review material flows, current and future product development, and supplier performance on quality, cost, and time.

- Developing a supplier quality measurement and evaluation process.

The ultimate goal of these efforts is to create and sustain supply chain quality and excellence through effective utilization of human, physical and intangible resources. 


\section{Conclusion}

This chapter has highlighted four key points:

1. Quality management and supply chain management are positively related.

2. Embedded within this relationship is a process management perspective.

3. Best practices in supply chain quality management can be found within the principles of Total Quality Management.

4. The transition to supply chain quality management requires knowledge in all three areas: processes, quality and supply chain management.

Since the quality movement began, improvements in one area enhance results in the other as quality management and supply chain management are clearly interdependent. Continuous quality improvements impact positively upon inventory levels, product and process variation, cycle times, responsiveness, flexibility, and ultimately, final customer satisfaction. As a result, quality management and supply chain management should be pursued simultaneously as a 'complete' integrated system. Clearly managers realize this relationship exists as we cited several examples of quality tools and techniques impacting upon supply chain processes. Specifically, in the design process, positive results occur through using concurrent engineering, design for manufacturability, value engineering, quality function deployment, and supplier-customer integration. Production, delivery and support processes can be improved through using surveys, six sigma programs, value analysis, value engineering, and benchmarking. Since components account for over 55\% of the cost of goods, supplier-customer relationships are critical to providing the right good, in the right quantity, at the right price, at the right place, at the right time to the customer. Incorporating supplier certification programs, and in particular, the eight key principles of Total Quality Management, into these relationships can reap tremendous rewards for all members. Of course, critical to this relationship development is the underlying trust and information sharing that occurs through co-makership. Hence, current managerial thinking needs to shift from traditional firm-centric and product-based mindset to an inter-organizational supply chain system. Supply chain quality management, which is strategic, tactical and operational approach, is required to bring about this change to an inter-organizational process that involves customers, suppliers and partners, and effectively compete in today's business environment. The key Total Quality Management practices in leadership, strategic planning, human resources management, supplier quality management, customer focus and process management are the foundation for supply chain quality management best practices. The transition to supply chain quality management will require a cultural change which will not happen overnight. It requires long-term thinking, evaluation of each member's strengths and weaknesses, improvements in communication and transportation infrastructures, and a culture of continuous improvement. In the future, companies that will excel in the global marketplace will incorporate supply chain quality management to bridge the gaps that exist in design, production, delivery, support, and supplier-customer relationship processes.

\section{References}

Adebanjo, D., Abbas, A., \& Mann, R. (2010). An investigation of the adoption and implementation of benchmarking. International Journal of Operations $\mathcal{E}$ Production Management, Vol. 30, No. 11, (2010), pp. 1140-1169. 
American Society for Quality Online Glossary (2011). Quality. Accessed on March 6, 2011. http://asq.org/glossary/q.html

Cox, J., \& Blackstone, John Jr. (Eds.) (2002). APICS Dictionary, Tenth Edition APICS - The Educational Society for Resource Management. Alexandria, VA.

Avery, S. (2002). Suppliers go the distance for Schneider Electric. Purchasing. Boston. Jul 18, 2002. Vol. 131, No. 12; pg. 53-57.

Azar, A., Kahnali, R.A., \& Taghavi, A. (2010). Relationship between Supply Chain Quality Management Practices and their Effects on Organisational Performance. Singapore Management Review, 2010 1st Half, Vol. 32, No. 1, pp. 45-68.

Benstin, M.S., Benston, D.P., \& Haraburda, S.S. (2011). Using Value Engineering to Reduce Life Cycle Costs. Defense ATEL, Jan/Feb2011, Vol. 40, No. 1, pp. 31-34.

Blaney, D. (2005). Constructive criticism. Supply Management, Vol. 10, No. 12, pg. 19.

Brockwell, J. (2011). Strategies for Strategic Sourcing. Industry Week/IW., Jan2008, Vol. 257, No. 1, pp. 28-30.

Chu-Hua, K., Madu, C., Chinho, L., \& Wing, S.C. (2002). Developing supply chain strategies based on the survey of supply chain quality and technology management. The International Journal of Quality and Reliability Management. Bradford: 2002. Vol. 19, No.. 6/7; pp. 889-302.

Evans, J., \& Lindsay, W. (2002). The Management and Control of Quality, Fifth Edition. SouthWestern College Publishing, Cincinnati, Ohio.

Ferdows, K., Lewis, M.A., and Machuca, J.A.D. (2004). Rapid-fire fulfillment. Harvard Business Review, Vol. 8, No. 11, pp. 104-110.

Flynn, B. B., \& Flynn, E. J. (2005). Synergies between supply chain management and quality management: emerging implications. International Journal of Production Research, Vol. 43, No. 16, 15 August 2005, pp. 3421-3436.

Flynn, B.B., Schroeder, R.G. and Sakakibara, S. (1995). The Impact of Quality Management Practices on Performance and Competitive Advantage. Decision Sciences, Vol. 26, No. 5, Sept/Oct 1995, pp. 659-691.

Foster, S.T. Jr. (2008). Towards an understanding of Supply Chain Quality Management. Journal of Operations Management, Vol. 26, pp. 461-467.

Foster, S. T. Jr., \& Ogden, J. (2008). On differences in how operations and supply chain managers approach quality management. International Journal of Production Research, Vol. 46, No. 24, 15 December 2008, pp. 6945-6961.

Heizer, J. \& Render, B. (2006). Principles of Operations Management $6^{\text {th }}$ Edition. Pearson: Prentice Hall, Upper Saddle River, NJ.

Heiko, L. (1990). Production lead time minimisation and just-in-time. Operations Management Review, vol. 3, No. 3-4, pp. 19-23.

Hulta, G.T.M. \& Swan, K.S. (2003). A research agenda for the nexus of product development and supply chain management processes. Journal of Product Innovation Management, Vol. 20, No. 6, 427-429.

Joglekar, N. \& Rosenthal, R. (2003). Coordination of design supply chains for bundling physical and software products. Journal of Product Innovation Management, Vol. 20, No. 5, 374-390.

Kaynak, H. \& Hartley, J. (2008). A replication and extension of quality management into the supply chain. Journal of Operations Management, Vol. 26, No. 4, pp. 468-489. 
Krajewski, L.J., Ritzman, L.P., \& Malhotra, M.K. (2010). Operations Management: Processes $\mathcal{E}$ Supply Chains. Pearson Education, Inc., Upper Saddle River, NJ.

Kuei, C., Madua, C. \& Lin, C. (2008). Implementing Supply Chain Quality Management. Total Quality Management, Vol. 19, No. 11, pp. 1127-114.

Lee, H.L. \& Sasser, M.M. (1995). Product universality and design for supply chain management. Production Planning \& Control, Vol. 6, No. 3, pp. 270-277.

Lee, K., Wei, C. \& Lee, H. (2009). Reducing exposed copper on annual rings in a PCB factory through implementation of a Six Sigma project. Total Quality Management $\mathcal{E}$ Business Excellence, Aug2009, Vol. 20, No. 8, pp. 863-876.

Mefford, R.M. (1989). The productivity nexus of new inventory and quality control techniques. Engineering Costs E Production Economy, 17, pp. 21-28.

Monczka, R.M., Handfield, R.B., Giunipero, L.C., \& Patterson, J.L. (2009). Purchasing and Supply Chain Management, Fourth Edition. South-Western Cengage Learning, Mason, $\mathrm{OH}$.

Murphy, W.H. (2010). Bull's-eye. Quality Progress. Milwaukee: Jun 2010. Vol. 43, No. 6, pp. 22.

Novak, S. \& Eppinger, S. (2001). Sourcing by design: Product complexity and the supply chain. Management Science, Vol. 47, No. 1, Jan. 2001, pp. 189-204.

Pagell, M. (2004). Understanding the factors that enable and inhibit the integration of operations, purchasing and logistics. Journal of Operations Management, Vol. 222, pp. 459-487.

Perry, M. \& Sohal, A. (1999). Improving service quality within the supply chain. Total Quality Management; Abingdon; July 1999, Vol. 10, No. 4/5, pp. 673-8.

Pilkington, A. \& Dyerson, R. (2002). Extending simultaneous engineering: Electric vehicle supply chains and new product development. International Journal of Technology Management. Geneva: 2002. Vol. 23, No. 1, 2, 3; pp. 74.

Reiner, G. \& Hofmann, P. (2006). Efficiency analysis of supply chain processes. International Journal of Production Research, Vol. 44, Issue 23, pp. 5065-5087.

Roethlein, C., Managiameli, P., \& Ebrahimpour, M. (2000). Inter-organizational effects of quality on a connected manufacturing supply chain: An exploratory case study. Decision Sciences Institute 2000 Proceedings, Orlando, FL, November 2000, pp. 120911.

Robinson, C.J. \& Malhotra, M. K. (2005). Defining the concept of Supply Chain Quality Management and its relevant to academic and industrial practice. International Journal of Production Economics, Vol. 96, pp. 315-337.

Salvador, F. \& Forza, C. (2003). Configuring products to address the customizationresponsiveness squeeze: A survey of management issues and opportunities. International Journal of Production Economics, Vol. 91, pp. 273-291.

Sila, I., Ebrahimpour, M., \& Brikholz, C. (2006). Quality in Supply Chains: An Empirical Study. Supply Chain Management: An International Journal, Vol. 11, No. 6, pp. 491502.

Simchi-Levi, D., Kaminksy, P. , \& Simchi-Levi, E. (2008). Designing \& Managing the Supply Chain: Concepts, Strategies and Case Studies, Third Edition. McGraw-Hill, NY, NY.

Tague, N.R. (2004). The Quality Toolbox, Second Edition, ASQ Quality Press, Milwaukee, WI.

Trent, R.J. and Monczka, R.M. (1999). Achieving world-class supplier quality. Total Quality Management, Vo. 19, No. 10, pp. 927-938. 
Yeung, A.C. L. (2008). Strategic supply management, quality initiatives, and organizational performance. Journal of Operations Management, Vol. 26, pp. 490-502. 


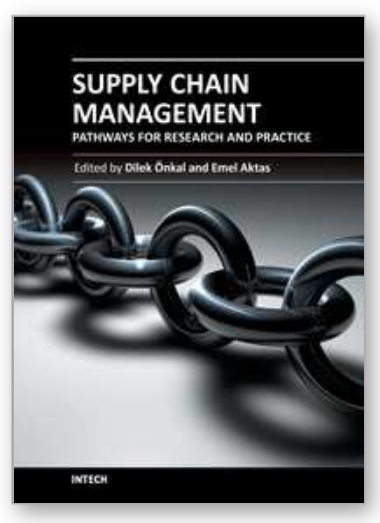

\author{
Supply Chain Management - Pathways for Research and Practice \\ Edited by Prof. Dilek Onkal
}

ISBN 978-953-307-294-4

Hard cover, 234 pages

Publisher InTech

Published online 01, August, 2011

Published in print edition August, 2011

Challenges faced by supply chains appear to be growing exponentially under the demands of increasingly complex business environments confronting the decision makers. The world we live in now operates under interconnected economies that put extra pressure on supply chains to fulfil ever-demanding customer preferences. Relative attractiveness of manufacturing as well as consumption locations changes very rapidly, which in consequence alters the economies of large scale production. Coupled with the recent economic swings, supply chains in every country are obliged to survive with substantially squeezed margins. In this book, we tried to compile a selection of papers focusing on a wide range of problems in the supply chain domain. Each chapter offers important insights into understanding these problems as well as approaches to attaining effective solutions.

\title{
How to reference
}

In order to correctly reference this scholarly work, feel free to copy and paste the following:

Lynn A. Fish (2011). Supply Chain Quality Management, Supply Chain Management - Pathways for Research and Practice, Prof. Dilek Onkal (Ed.), ISBN: 978-953-307-294-4, InTech, Available from: http://www.intechopen.com/books/supply-chain-management-pathways-for-research-and-practice/supplychain-quality-management

\section{INTECH}

open science | open minds

\author{
InTech Europe \\ University Campus STeP Ri \\ Slavka Krautzeka 83/A \\ 51000 Rijeka, Croatia \\ Phone: +385 (51) 770447 \\ Fax: +385 (51) 686166 \\ www.intechopen.com
}

\author{
InTech China \\ Unit 405, Office Block, Hotel Equatorial Shanghai \\ No.65, Yan An Road (West), Shanghai, 200040, China \\ 中国上海市延安西路65号上海国际贵都大饭店办公楼405单元 \\ Phone: +86-21-62489820 \\ Fax: +86-21-62489821
}


(C) 2011 The Author(s). Licensee IntechOpen. This chapter is distributed under the terms of the Creative Commons Attribution-NonCommercialShareAlike-3.0 License, which permits use, distribution and reproduction for non-commercial purposes, provided the original is properly cited and derivative works building on this content are distributed under the same license. 